\title{
Renal function in acute falciparum malaria
}

\author{
A Sowunmi
}

\begin{abstract}
Renal function was assessed in $\mathbf{4 0}$ children during the acute illness and after recovery from falciparum malaria. Creatinine clearance was significantly lower during the acute illness than after recovery. Six of 18 children with impaired creatinine clearance $\left(<50 \mathrm{ml} / \mathrm{min} / 1 \cdot 73 \mathrm{~m}^{2}\right)$ had evidence of acute tubular dysfunction. Hyponatraemia occurred in $12.5 \%$ during the acute phase. Fractional sodium excretion was raised in $27 \%$ during the acute illness and continuing sodium wastage occurred in $17 \%$ after recovery. Plasma potassium was significantly higher and fractional potassium excretion $\left(\mathrm{Fe}_{\mathrm{K}}\right)$ significantly lower during the acute illness than after recovery. There was a positive correlation between $\mathrm{Fe}_{\mathrm{Na}}$ and $\mathrm{Fe}_{\mathrm{K}}$ both during and after recovery from the illness but they did not exactly mirror each other in every individual. Urine sodium:potassium ratios were similar during and after recovery from the illness and was related to $\mathrm{Fe}_{\mathrm{Na}}$. Fractional glucose excretion was zero. Mild proteinuria occurred in $40 \%$ during the acute illness but were not related to creatinine clearance, body temperature at presentation, or peripheral parasite density. Proteinuria was absent after recovery. Acute intrinsic renal impairment occurs during apparently 'uncomplicated' falciparum malaria in children.

(Arch Dis Child 1996; 74: 293-298)
\end{abstract}

Keywords: falciparum malaria, renal function indices, hyponatraemia, hyperkalaemia.

Falciparum malaria is a major cause of morbidity and mortality in African children, 12 and is frequently complicated by metabolic, respiratory, and cerebral involvement, ${ }^{34}$ but renal complications are less frequently documented. Assessment of renal function in acute malaria in Indian children has shown that endogenous creatinine clearance was reduced during the acute illness and returned to normal after recovery. ${ }^{5}$ There is little or no information on renal function in African children suffering from acute falciparum malaria.

The present study, a prospective investigation of renal function in African children with acute falciparum malaria, was designed to determine the effects of the disease on renal function.

\section{Methods}

PATIENTS

The study was part of a wider study of renal pathophysiological changes in falciparum malaria in children, ethical permission for which was given by the joint University of Ibadan/University College Hospital, Ibadan, ethics committee. A patient was recruited into the study if the following criteria were met: fever or a history of fever in the 24-48 h preceding presentation, other symptoms of malaria, pure Plasmodium falciparum parasitaemia, clear consciousness, absence of bronchopneumonia or other complicating illness, no previous history suggestive of renal disease, no history of antimalarial drug administration in the two weeks preceding presentation, and consent of parents or guardians.

\section{PROCEDURES}

Before enrolment into the study, all children had a thorough history taken followed by a detailed clinical examination. Thereafter oral or rectal temperature was taken, the weight was measured and a thick and thin blood film was obtained from a finger prick and Giemsa stained for parasitaemia quantification. Parasitaemia was quantified in thick films by counting parasites against white blood cells, and in thin films by counting 1000 red blood cells in clear contiguous fields and finding the proportion parasitised.

Each subject completely emptied the bladder and the voided urine was immediately tested for protein, blood, glucose, ketones, urobilinogen, bilirubin, nitrites, and $\mathrm{pH}$ using a dipstick (Multistix, Ames). Thereafter a creatinine clearance study was begun $(0 \mathrm{~h})$; urine was collected over $6 \mathrm{~h}$ (supervised) and blood was taken at $3 \mathrm{~h}$ for plasma electrolytes, urea, creatinine, uric acid, and glucose estimation. In order to promote urine flow, oral fluid was given at a rate of $5 \mathrm{ml} / \mathrm{kg} / \mathrm{h}$. At the end of $6 \mathrm{~h}$ the total urine volume was measured and the urinalysis repeated. A $10 \mathrm{ml}$ aliquot was immediately stored frozen at $-20^{\circ} \mathrm{C}$ until analysed for urine glucose, electrolytes, urea, uric acid, and creatinine. Glucose was estimated in undiluted urine, and plasma and an aqueous standard by a glucose oxidase photometric method on an Analox GM6 microstat analyser. The coefficient of variation at concentrations of $1-10$ $\mathrm{mmol} / \mathrm{l}$ was less than $1 \cdot 5 \%$. Plasma sodium and potassium were determined on a Hitachi 704 autoanalyser (Boehringer Mannheim). Urine sodium and potassium were determined with a Corning $410 \mathrm{C} \mathrm{Na}{ }^{+} / \mathrm{K}^{+}$analyser (Ciba Corning). The coefficient of variation was less than $1 \%$ of all plasma sodium and potassium measurements and less than $1 \%$ of all urine sodium and potassium measurements over the concentration range of 5-200 $\mathrm{mmol} / \mathrm{l}$. Creatinine and urea were measured 
in plasma and urine with a Beckman creatinine analyser 2 and a Beckman BUN analyser 2 respectively. The coefficient of variation was less than $1 \cdot 2 \%$.

Each patient was treated with intramuscular artemether $3.2 \mathrm{mg} / \mathrm{kg}$ body weight at presentation $(0 \mathrm{~h})$ followed by $1.6 \mathrm{mg} / \mathrm{kg}$ body weight daily for the next $4 \mathrm{~d}$ (days 1-4). All the children were personally treated by the author. Each patient was seen daily for eight days (days $0-7)$ and then on day 14. At each visit, each parent or guardian (and where possible, the child) was questioned regarding wellbeing and adverse drug reaction, and a physical examination was again performed. Thick and thin blood films for parasitaemia quantification were also examined at each visit.

On day 7 , when parasitaemia, fever, and other symptoms of malaria had cleared completely, a repeat creatinine clearance study was done (as described during the acute illness).

The parasite clearance time was defined as the time from drug administration until there was no evident parasitaemia for at least $48 \mathrm{~h}$. The fever clearance time was defined as the time from drug administration until the core temperature fell to or below $37 \cdot 2^{\circ} \mathrm{C}$ and remained so for at least $48 \mathrm{~h}$. Body surface area was determined from a standard nomogram ${ }^{6}$ using height and weight. Creatinine clearance and fractional sodium and potassium excretion were calculated from standard equations. ${ }^{7}$ Differentiation of acute tubular necrosis from prerenal azotaemia was by standard formulae. ${ }^{8-10}$ The measured creatinine clearance was compared with that determined by the formula of Schwartz et al. ${ }^{11}$

\section{STATISTICS}

Statistical analysis was by the Student's $t$ test, $\chi^{2}$ tests with Yates's correction, and regression analyses. Values are given in text and, where necessary, in the tables as mean (SD); $p$ values less than 0.05 were taken as significant.

\section{Results}

Fifty consecutive children were studied between July and November 1993; 40 patients completed the study and were analysed. In the remaining 10 children, incomplete urine collection during the acute illness or acute illness and recovery led to exclusion from the analysis of the results. Parasitaemia and fever cleared in all the 10 children within $72 \mathrm{~h}$, with no recurrence during the $14 \mathrm{~d}$ period of follow up.

CLINICAL AND PARASITOLOGICAL RESPONSE

Table 1 summarises the clinical findings at presentation in the 40 children. All patients were febrile at or within $12 \mathrm{~h}$ of presentation. No patient had symptoms referable to the genitourinary system. The mean fever clearance time was $1 \cdot 1(0 \cdot 2)$ days [range $1-3$ ] and the mean parasite clearance time was $1.9(0.8)$ days [range 1-4]. There was no recurrence of fever or parasitaemia during the two weeks of follow up in all the children.
Table 1 Clinical features in 40 children with falciparum malaria

\begin{tabular}{lc}
\hline Fever & 40 \\
Chills/rigors & 11 \\
Anorexia & 12 \\
Vomiting & 17 \\
Diarrhoea & 6 \\
Abdominal pain & 8 \\
Headache & 15 \\
Urinary symptoms & 0 \\
Duration of symptoms (days) & $1-21$ \\
$\quad$ Range & $3 \cdot 3(3 \cdot 1)$ \\
Mean (SD) & $36 \cdot 8-40 \cdot 7$ \\
Initial temperature $\left({ }^{\circ} \mathrm{C}\right)$ & $38 \cdot 4(1 \cdot 0)$ \\
$\quad$ Range & \\
$\quad$ Mean (SD) & $1180-667000$ \\
Initial parasite density (per $\mu \mathrm{l})$ & 20067 \\
$\quad$ Range & $1-3$ \\
$\quad$ Mean (geometric) & $1 \cdot 9(0 \cdot 8)$ \\
Parasite clearance time (days) & \\
$\quad$ Range & $0-5$ \\
Mean (SD) & $1 \cdot 1(0 \cdot 2)$ \\
$\quad$ Rever clearance time (days) & \\
$\quad$ Mean (SD) & \\
Cure rate on day $14(\%)$ & \\
\end{tabular}

ENDOGENOUS CREATININE CLEARANCE AS A MEASURE OF GLOMERULAR FILTRATION RATE Plasma creatinine was raised $(>81 \mu \mathrm{mol} / \mathrm{l})$ in six of $40(15 \%)$ children during the acute illness and was normal in all but one $(91 \mu \mathrm{mol} / \mathrm{l})$ after recovery. Figure 1 shows the creatinine clearance values during the acute illness and after recovery from the illness. Creatinine clearance was lower during the acute illness than after recovery $[63.9(49.3) v$ $93.3(44.8) \mathrm{ml} / \mathrm{min} / 1.73 \mathrm{~m}^{2}, \mathrm{df}=38, t=6.33$, $\mathrm{p}<0.001 ; 95 \%$ confidence interval $(95 \% \mathrm{CI})$ for the difference, $19 \cdot 3$ to $36 \cdot 6]$. Creatinine clearance was impaired $\left(<50 \mathrm{ml} / \mathrm{min} / 1.73 \mathrm{~m}^{2}\right)$ in 18 of 40 children ( $45 \%$ ) and returned to normal after recovery in all but three. The other indices of renal function in children with impaired creatinine clearance during the acute illness are shown in table 2 . Four of the children had features of incipient polyuric acute tubular dysfunction and another two of incipient acute anuric tubular dysfunction, associated with hyperkalaemia of 5.6 and $6 \cdot 1 \mu \mathrm{mol} / 1$. Other indices of renal function were normal in the remaining 12 children with impaired creatinine clearance. Proteinuria (mild, 10-100 $\mathrm{mg} / \mathrm{dl}$ ) occurred in eight patients with impaired creatinine clearance and in eight with normal creatinine clearance. There was no significant difference in the proportion of children with proteinuria in the two groups $\left(\chi^{2}=0 \cdot 305, p>0 \cdot 2\right)$. There was no correlation between peripheral parasite density and creatinine clearance during the acute illness $(r=0 \cdot 14, t=0 \cdot 123, \mathrm{p}>0 \cdot 2)$. Creatinine clearance during the acute illness, however, correlated with that predicted by the formula of Schwartz et $a l^{11} \quad(r=0.639, \quad t=3.44$, $\mathrm{p}<0.001$ ).

\section{SODIUM EXCRETION}

Plasma sodium $\left(\mathbf{P}_{\mathrm{Na}}\right)$ was normal (130$145 \mu \mathrm{mol} / \mathrm{l})$ in 35 of 40 children $(87.5 \%)$; hyponatraemia $\left(\mathrm{P}_{\mathrm{Na}}<130 \mu \mathrm{mol} / \mathrm{l}\right)$ occurred in five $(12 \cdot 5 \%)$. Plasma sodium was significantly lower during the acute illness than after recovery [134 (4.4) $v 136.2(2.9) \mu \mathrm{mol} / \mathrm{l}$, $t=2.538, \mathrm{p}<0.02 ; 95 \%$ CI for the difference, 


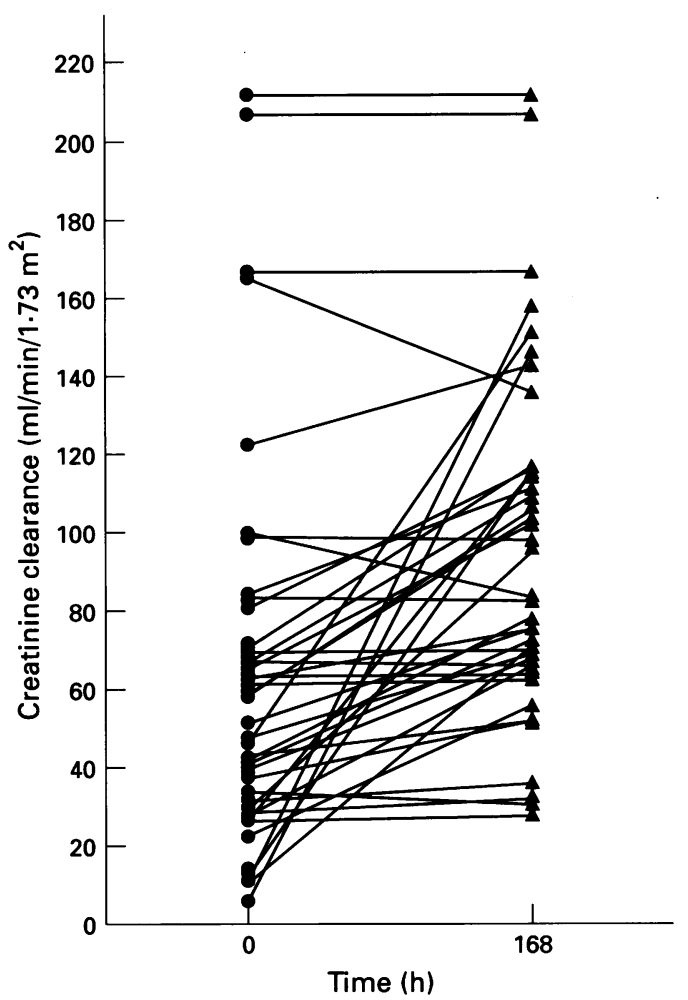

Figure 1 Endogenous creatinine clearance during (๑) and after (৯) recovery from acutr falciparum malaria.

0.37 to 4.39 . There was no correlation between parasite density and plasma sodium concentration $(r=0.079, t=0.49, \mathrm{p}>0.2)$.

Fractional sodium excretion $\left(\mathrm{Fe}_{\mathrm{Na}}\right)$ was lower during the acute illness than after recovery but the difference was not statistically significant $\left[\begin{array}{lllll}0.95 & (0.98) & v & 1.39 & (1.82) \% \text {, }\end{array}\right.$ $t=1.95, \mathrm{p}>0.05$, see below]. This difference was due to continuing massive sodium loss in three children despite complete resolution of malaria symptoms and parasitaemia. $\mathrm{Fe}_{\mathrm{Na}}$ values greater than $2 \%$ occurred in 11 of 40 children $(27.5 \%)$ during the acute illness [mean (SD) $3 \cdot 15(0 \cdot 99 \%)$, range $2 \cdot 1-4 \cdot 69$ ]. In eight of these, the value was reduced to less than $2 \%$ after recovery. In three other children, a further increase was seen to values of $63.9 \%$, $44 \cdot 8 \%$, and $3 \cdot 0 \%$ from $2 \cdot 1 \%, 3 \cdot 2 \%$, and $2 \cdot 7 \%$ respectively. In 26 patients with $\mathrm{Fe}_{\mathrm{Na}}$ less than $2 \%$ during the acute illness, a reduction or no change was observed after recovery. Four patients with $\mathrm{Fe}_{\mathrm{Na}}$ values less than $1.5 \%$ during the acute illness had increases to values of $>3.8 \%$ after recovery (table 3 ). Three of these children had creatinine clearance values less than $50 \mathrm{ml} / \mathrm{min} / 1.73 \mathrm{~m}^{2}$ during the acute ill- ness, and a return normal values after recovery occurred in two of these. The only patient with normal creatinine clearance during and after recovery who had continuing urinary sodium loss developed hyponatraemia after recovery (table 3). These observations suggest that there was continuing renal tubular dysfunction despite complete recovery from acute falciparum malaria.

\section{POTASSIUM EXCRETION}

Hyperkalaemia occurred in two children during the acute illness but in no patient after recovery. The children with hyperkalaemia had evidence of incipient anuric acute tubular dysfunction (table 2). There were no other complications associated with hyperkalaemia. Plasma potassium was higher during the acute illness than after recovery $[4.21(0.63) v 3.73$ $(0.35) \mu \mathrm{mol} / 1, \mathrm{df}=33, t=3.73, \mathrm{p}<0.001 ; 95 \%$ $\mathrm{CI}$ for the difference, $0 \cdot 16$ to $0 \cdot 51$ ). Fractional potassium excretion $\left(\mathrm{Fe}_{\mathrm{K}}\right)$ was lower during the acute illness than after recovery $[15.35$ (8.56) v 32.5 $(34.7) \%, \quad \mathrm{df}=34, \quad t=3.94$, $\mathrm{p}<0.01 ; 95 \%$ CI for the difference, 15.44 to 44.72].

RELATION BETWEEN FE ${ }_{\mathrm{NA}}$ AND $\mathrm{FE}_{\mathrm{K}}$

During the acute illness there was a positive correlation between $\mathrm{Fe}_{\mathrm{Na}}$ and $\mathrm{Fe}_{\mathrm{K}}(r=0.405$, $t=2.66, \mathrm{p}<0.01 ; 95 \%$ CI for $r, 0.108$ to 0.702 , $\mathrm{n}=40$ ), although sodium and potassium excretion did not exactly mirror each other in every individual. Similarly, there was a positive correlation between these two variables after recovery $(r=0.488, t=3.31, \mathrm{p}<0.001 ; 95 \% \mathrm{CI}$ for $r, 0.20$ to $0 \cdot 776, \mathrm{n}=37$ ). Again, in individual children sodium and potassium excretion did not exactly mirror each other.

\section{URINE SODIUM:POTASSIUM RATIO}

Urine sodium:potassium ratio ranged from 0.98 to $12 \cdot 22$ during the acute illness and from 1.51 to 15.9 after recovery. Over all, urine sodium: potassium ratio was lower during the acute illness than after recovery, but the difference was not statistically significant $[4 \cdot 22(2 \cdot 66) v 5 \cdot 28$ (3.2), $t=1 \cdot 39, \mathrm{p}>0 \cdot 1, \mathrm{n}=37]$. The relation between the urine sodium:potassium ratio and fractional sodium excretion $\left(\mathrm{Fe}_{\mathrm{Na}}\right)$ during and after recovery from illness is shown in figs 2 and 3. There was a positive correlation between this ratio and fractional sodium excretion during the acute illness $(r=0.484, t=3.331, \mathrm{p}<0.001 ; 95$

Table 2 Indices of renal function in children with reduced creatinine clearance $\left(<50 \mathrm{ml} / \mathrm{min} / 1 \cdot 73 \mathrm{~m}^{2}\right)$ and evidence of renal tubular dysfunction

\begin{tabular}{|c|c|c|c|c|c|c|c|c|}
\hline $\begin{array}{l}\text { Code No } \\
R F\end{array}$ & $\begin{array}{l}\text { Creatinine clearance } \\
\left(\mathrm{ml} / \mathrm{min} / 1.73 \mathrm{~m}^{2}\right)\end{array}$ & $\begin{array}{l}F e_{N a} \\
(\%)\end{array}$ & $\begin{array}{l}F e_{K} \\
(\%)\end{array}$ & $\frac{U c r}{P c r}$ & $R F I$ & $\begin{array}{l}\text { Urine volume } \\
(0-6 \mathrm{~h})(\mathrm{ml})\end{array}$ & $\begin{array}{l}\text { Urine protein } \\
(\mathrm{mg} / \mathrm{dl})\end{array}$ & Comment \\
\hline $\begin{array}{l}15 \\
16 \\
26 \\
34 \\
38 \\
44\end{array}$ & $\begin{array}{l}13 \cdot 0 \\
45 \cdot 2 \\
38 \cdot 7 \\
11 \cdot 1 \\
25 \cdot 2 \\
30 \cdot 9\end{array}$ & $\begin{array}{l}4 \cdot 46 \\
3 \cdot 42 \\
3 \cdot 29 \\
2 \cdot 4 \\
3 \cdot 4 \\
4 \cdot 21\end{array}$ & $\begin{array}{l}30 \cdot 08 \\
48 \cdot 98 \\
14 \cdot 57 \\
21 \cdot 7 \\
11 \cdot 4 \\
10 \cdot 5\end{array}$ & $\begin{array}{r}2 \cdot 8 \\
4 \cdot 1 \\
19 \cdot 4 \\
4 \cdot 3 \\
4 \cdot 7 \\
6 \cdot 2\end{array}$ & $\begin{array}{l}6 \cdot 4 \\
4 \cdot 63 \\
4 \cdot 22 \\
2 \cdot 79 \\
4 \cdot 46 \\
5 \cdot 64\end{array}$ & $\begin{array}{r}750 \\
1000 \\
400 \\
285 \\
210 \\
570\end{array}$ & $\begin{array}{r}0 \\
10 \\
0 \\
0 \\
0 \\
0\end{array}$ & $\begin{array}{l}\text { Incipient polyuric, ATD } \\
\text { Incipient polyuric, ATD } \\
\text { Incipient polyuric, ATD, hyperkalaemia } \\
\text { Incipient anuric, ATD } \\
\text { Hyperkalaemia, incipient anuric, ATD } \\
\text { Incipient polyuric, ATD }\end{array}$ \\
\hline
\end{tabular}

$\mathrm{Fe}_{\mathrm{Ng}}=$ factional sodium excretion $\mathrm{Fe}_{\mathrm{K}}=$ fractional potassium excretion; $\mathrm{Ucr}=$ urine creatinine; $\mathrm{Pcr}=$ plasma creatinine; RFI=rena failure index; ATD $=$ acute tubular dysfunction; $0=$ no proteinuria. ${ }^{\star}$ No blood in urine in all patients. 
Table 3 Indices in four children with normal fractional sodium excretion during acute illness and increased excretion after recovery

\begin{tabular}{|c|c|c|c|c|c|c|}
\hline \multirow{2}{*}{$\begin{array}{l}\text { Code No } \\
R F\end{array}$} & \multicolumn{2}{|c|}{$\begin{array}{l}\text { Creatinine clearance } \\
\left(\mathrm{mL} / \mathrm{min} / 1 \cdot 73 \mathrm{~m}^{2}\right)\end{array}$} & \multicolumn{2}{|c|}{ 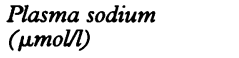 } & \multicolumn{2}{|c|}{$\begin{array}{l}\text { Fractional sodium } \\
\text { excretion }(\%)\end{array}$} \\
\hline & Acute & Recovery & Acute & Recovery & Acute & Recovery \\
\hline $\begin{array}{r}4 \\
22 \\
24 \\
33\end{array}$ & $\begin{array}{l}36 \cdot 6 \\
31 \cdot 2 \\
97 \cdot 5 \\
46 \cdot 8\end{array}$ & $\begin{array}{l}51 \\
35 \cdot 3 \\
97 \cdot 3 \\
65\end{array}$ & $\begin{array}{l}136 \\
126 \\
136 \\
134\end{array}$ & $\begin{array}{l}141 \\
136 \\
129 \\
137\end{array}$ & $\begin{array}{l}0.98 \\
0.97 \\
1.97 \\
1.27\end{array}$ & $\begin{array}{l}3 \cdot 80 \\
5 \cdot 50 \\
8 \cdot 72 \\
63 \cdot 9\end{array}$ \\
\hline
\end{tabular}

CI for $r, 0.208$ to $0.76, \mathrm{n}=40$ ) and after recovery $(r=0.333, t=2.07, \mathrm{p}<0.04 ; 95 \%$ CI for $r$, 0.616 to $0.648, n=36$ ). Thus a scattergram of urine sodium:potassium ratio is similar to that of sodium excretion. The relatively similar sodium:potassium ratio during and after recovery would suggest insignificant disturbance of the sodium/potassium exchange mechanisms in the distal renal tubule by the malaria process.

\section{GLUCOSE EXCRETION}

Plasma glucose varied between 2.7 and 6.0 [mean $4.6(0 \cdot 7)$ ] $\mathrm{mmol} / \mathrm{l}$ during the acute illness and between 3.0 and 6.2 [mean $4.9(0.3)$ ] $\mathrm{mmol} / \mathrm{l}$ after recovery. There was no significant difference between these values $(p>0 \cdot 2)$. Glucose was not detected in any urine sample during and after recovery from the illness. Thus fractional glucose excretion was zero per cent.

\section{HYPONATRAEMIA AND THE SYNDROME OF} INAPPROPRIATE ANTIDIURETIC HORMONE SECRETION (SIADH)

The clinical criteria for the diagnosis of SIADH adopted in the present study were: normal creatinine clearance $\left(>80 \mathrm{ml} / \mathrm{min} / 1.73 \mathrm{~m}^{2}\right)$,

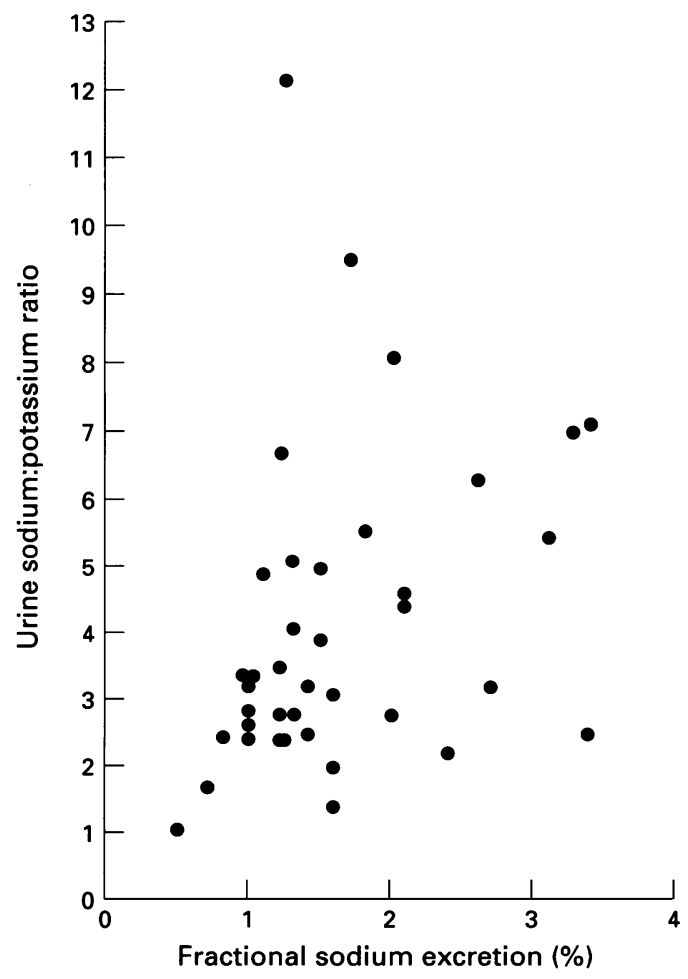

Figure 2 Relation between urine sodium:potassium ratio and fractional sodium excretion during acute falciparum malaria in children.

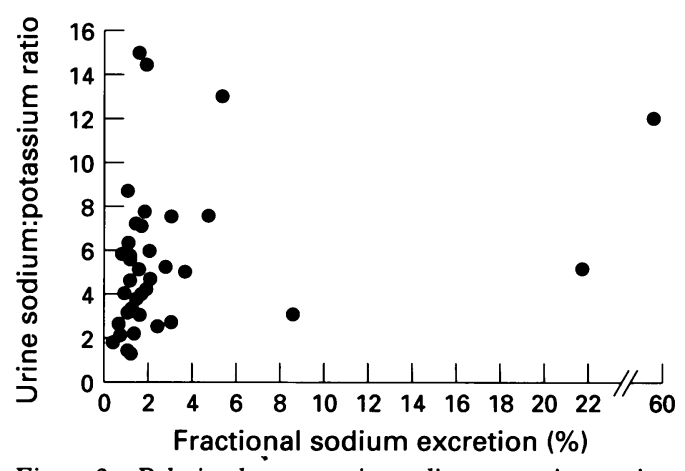

Figure 3 Relation between urine sodium:potassium ratio and fractional sodium excretion after recovery from malaria in children.

$\mathrm{Fe}_{\mathrm{Na}}>2 \%$, plasma sodium $<130 \mu \mathrm{mol} / \mathrm{l}$, and plasma uric acid $<0.11 \mathrm{mmol} / 1$ in the absence of hypovolaemia or hypotension. Only one child satisfied these criteria and was considered to have the SIADH secretion during the acute illness. The blood pressure in this child was $95 / 55 \mathrm{~mm} \mathrm{Hg}$ in the supine position. Plasma arginine vasopressin concentration was not determined in this patient.

\section{MISCELLANEOUS}

Table 4 summarises the findings on urinalysis during and after recovery from the illness. Proteinuria was present in 16 of 40 children (40\%) during the acute illness, was mild, and ranged between 10 and $100 \mathrm{mg} / \mathrm{dl}$. There was no relationship between proteinuria and body temperature $(r=0.239, \mathrm{p}>0.2)$ or between proteinuria and peripheral parasite density $(r=-0.001, \mathrm{p}>0.2)$. Nitrites were present in urine in nine of 40 children $(22.5 \%)$ during the acute illness and in one of 40 children $(2.5 \%)$ after recovery. Routine urine culture revealed no pathogenic organisms suggesting either insufficient nitrate in urine or non-nitrate reducing bacteria. Urine microscopy was not done in any patient.

\section{Discussion}

Despite the common occurrence of falciparum malaria in African children, the clinical features of malaria are as non-specific as are the clinical features of complications following acute infections. It was therefore not surprising that in none of the children studied were there symptoms or signs referable to the genitourinary system. This may be partly responsible for the low clinical index of suspicion of renal involvement in falciparum malaria in children.

In the present series, creatinine clearance, as

Table 4 Urinary findings during and after recovery

\begin{tabular}{lll}
\hline & \multicolumn{2}{l}{ Number of patients } \\
\cline { 2 - 3 } Characteristic & Acute & Recovery \\
\hline Protein & 16 & 0 \\
Blood & 0 & 0 \\
Urobilinogen & 3 & 0 \\
Bilirubin & 5 & 0 \\
Glucose & 0 & 0 \\
Nitrite & 9 & 1
\end{tabular}


a measure of glomerular filtration rate (GFR), was reduced during the acute illness and was severely impaired in $45 \%$ of the children. Except in a few, it returned to normal in all patients. This finding is in agreement with that of a previous study in Indian children. ${ }^{5}$ Urine composition analyses in children with impaired creatinine clearance revealed that incipient acute polyuric or anuric renal tubular dysfunction occurred in four and two children respectively during the acute illness. In the latter children, hyperkalaemia occurred. It would appear that untreated, these children could have progressed to frank acute renal failure (which again may not be readily apparent to the clinician). Thus impaired renal function is not as uncommon as was previously thought in African children with falciparum malaria. Hypotension, shock or haemoglobinuria would not adequately explain the impaired renal function in these children, although in untreated children, these may be contributory factors in the late stages. It is possible that parasite sequestration in the renal vascular (microvascular) bed may account for these changes, as hyperparasitaemia $(>5 \%$ parasitised erythrocytes ${ }^{12}$ ) occurred in $37.5 \%$ of the children. However, the absence of a significant correlation between peripheral parasite density and creatinine clearance during the acute illness suggests that peripheral parasite density or the sequestered parasites in the internal organs may not be the sole determining factor. Moreover, peripheral parasite density is not indicative of total body parasite load in any infected individual.

During the acute illness, plasma sodium was significantly lower than after recovery; hyponatraemia occurred in $12.5 \%$ of the children during the acute phase and was unrelated to peripheral parasite density. Hyponatraemia is not uncommon in falciparum malaria in children (Newton C R J C, Marsh K, unpublished) and has been reported in malaria in adults. ${ }^{13}$ The lack of a relation between parasite density and plasma sodium in the present report contrasts sharply with the findings of Miller et $a l^{13}$ in adults in which there was an association between hyponatraemia and severity of parasitaemia.

Fractional sodium excretion in the children showed four distinct patterns. In the majority of the children $(52 \%)$, this was normal throughout the period of observation. However, $27 \%$ had increased fractional sodium excretion during the acute illness, which returned to normal after recovery. A small proportion $(8 \%)$ had raised fractional sodium excretion during the acute illness with further increase after recovery. Finally, $13 \%$ of the children with normal fractional sodium excretion during the acute illness had a further increase at recovery. The features of the last two groups would suggest continuing renal tubular dysfunction despite recovery from the acute illness. Such renal dysfunction with or without normal creatinine clearance has been observed in children with cerebral malaria (paper in preparation).

The cause of the hyponatraemia in malaria in the present study is multifactorial. Vomiting, diarrhoea, and excessive sweating may lead to sodium loss. Other causes are renal sodium wasting, and, clinically, the syndrome of inappropriate antidiuretic hormone secretion (SIADH). The nature of the sodium wastage would suggest failure of proximal tubular reabsorption, although the distal tubule may also fail to compensate. However, the similar urine sodium to potassium ratio during and after recovery from the acute illness would suggest a relatively intact $\mathrm{Na}-\mathrm{K}$ exchange mechanism in the distal tubule. SIADH has been reported in malaria before, ${ }^{13}$ and has recently been proved in patients with severe malaria. ${ }^{14}$ Measurements of plasma antidiuretic hormone [(ADH), arginine vasopressin (AVP)] in African children with severe and complicated malaria have shown that excess AVP secretion occurs in this condition and is responsible for $31 \%$ of the cases of hyponatraemia in severe or cerebral malaria in children (paper in preparation). There are important clinical implications of this finding with respect to fluid management in falciparum malaria in children.

Plasma potassium was higher during the acute illness than after recovery, and hyperkalaemia occurred in $5 \%$ of the children in this series in association with other evidence of acute tubular dysfunction. It was, however, not associated with other symptoms and signs of hyperkalaemia. Although hyperkalaemia may be asymptomatic, it may cause sudden cardiac arrest and death. It is therefore not surprising that sudden death may occur in children with apparently 'uncomplicated' falciparum malaria. The higher fractional potassium excretion after recovery would suggest a compensating effect of renal tubules in clearing the 'excess' plasma potassium associated with the acute illness. This view is supported by the findings of a recent study of potassium excretion in sick neonates ${ }^{15}$ which showed that a fractional potassium excretion as high as $98 \%$ of filtered potassium was associated with hyperkalaemia. Alternatively, potassium wastage resulting from failure of tubular reabsorption (akin to sodium wastage above) may be responsible. This is possible since there is a relation between fractional sodium excretion and fractional potassium excretion during the acute illness. However, fractional sodium excretion and fractional potassium excretion did not exactly mirror each other in every individual child studied.

Neither hypoglycaemia nor hyperglycaemia were observed in the present series and no glucose was detected in the urine during acute illness or after recovery. Thus no significant glucose spillage occurred during the observation period. Glucose reabsorption in the proximal tubule depends on the $\mathrm{Na} / \mathrm{K}$-ATPase. Therefore in the present series, glucose conservation did not parallel fractional sodium excretion. The reasons are unclear, but may be due to a differential effect of the malaria process on the reabsorption of both substances. The not infrequent occurrence of 
hypoglycaemia in malaria ${ }^{1617}$ may mean that plasma glucose concentration may never increase above the threshold for saturation of the tubular transport mechanism, since glycosuria occurs only when the threshold is reached. ${ }^{18}$ The absence of significant glycosuria in malaria would suggest that polyuric acute tubular dysfunction that may complicate falciparum malaria cannot be attributed to the osmotic diuresis of glycosuria.

Proteinuria during the acute illness was mild and unrelated to the creatinine clearance. Proteinuria is not uncommon in febrile illnesses in children. However, it was not related to the body temperature during the acute illness. It may be that fever has an all or none effect on protein excretion in malaria or that a single temperature measurement does not accurately reflect the relation to proteinuria.

The evaluation of renal function in falciparum malaria in children should form an important part of the assessment of many acutely ill children with this disease. This is because of the wide variety of types of acute onset renal dysfunction that may attend this disease. In addition, it may facilitate safer prescribing of fluids, electrolytes, and drugs. The tendency to hyponatraemia in $13 \%$ of the patients and the hyperkalaemia that may attend acute tubular dysfunction during the acute illness illustrate this point. Although most commonly used antimalarials (with the possible exception of quinine ${ }^{19}$ ) are nonnephrotoxic, it is possible that adverse reactions to antimalarials may be increased in children with acute renal dysfunction.

The use of parenteral artemether in this series of children requires some justification. Artemether is not normally recommended for children without cerebral or complicated malaria. However, the rapid clearance of ring infected erythrocytes by this drug ${ }^{20} 21$ (and in the present study) reduces the chances of complicated malaria and therefore hastens recovery. Thus the postrecovery studies were quickly accomplished, minimising the default rate.
This study received financial support from the UNDP/World Bank/WHO Special Programme for Research and Training in Tropical Diseases. I am particularly grateful to J L Fajimi, Chief of Laboratory Services, Department of Chemical Pathology, University College Hospital, Ibadan, for the analysis of the biological samples.

1 Greenwood BM, Bradley AK, Greenwood AM, et al. Mortality and morbidity from malaria among children in a rural area of the Gambia, West Africa. Trans $R$ Soc Trop Med Hyg 1987; 81: 478-86.

2 Snow RW, Armstrong Schellenberg JRM, Peshu N, et al. Periodicity and space-time clustering of severe childhood malaria on the coast of Kenya. Trans $R$ Soc Trop Med Hyg 1993; 87: 386-90.

3 Newton CRJC, Kirkham FJ, Winstanley PA, et al. Intracranial pressure in African children with cerebral malaria. Lancet 1991; 337: 573-6.

4 Newton CRJC, Peshu N, Kendall B, et al. Brain swelling and ischaemia in Kenyans with cerebral malaria. Arch Dis Child 1994; 70: 281-4.

5 Ahmad SH, Danish T, Faridi MM, Ahmad AJ, Fakhir S, Khan AS. Renal function in acute malaria in children. Khan AS. Renal function in ac

F Trop Paediatr 1989; 35: 291-4.
6 Dubois EF. Basal metabolism in health and disease. Philadelphia: Lea and Ferbiger, 1936

7 Espinel CH. The FeNa test: use in the differential diagnosis of acute renal failure. $¥ A M A 1976 ; 236: 579-81$.

8 Rock RC, Walker CW, Jennings CD. Nitrogen metabolism and renal function. In: Tietz TW, ed. Textbook of clinical chemistry. Philadelphia: WB Saunders, 1986: 1254-316.

9 Handa SP, Morrin PAF. Diagnostic indices in acute renal failure. Can Med Assoc F 1967; 96: 78-82.

10 Finn FD. Diagnosis and management of acute tubular necrosis. Med Clin North Am 1990; 74: 873-91.

11 Schwartz GJ, Haycock GB, Edelman CM, Spitzer A. A simple estimate of glomerular filtration rate in children derived from body length and plasma creatinine. derived from body length
Paediatrics 1976; 58: 259-63.

12 World Health Organisation. Severe and complicated malaria. Trans $R$ Soc Trop Med Hyg 1992; 84 (suppl 2): malaria.

13 Miller LH, Makaranond P, Sitprija V, Suebsanguan C, Canfield CJ. Hyponatraemia in malaria. Ann Trop Med Parasitol 1967; 61: 265-79.

14 Holst HGE, Hemmer CJ, Kern P, Dietrich $M$ Inappropriate secretion of antidiuretic hormone and hyponatraemia in severe falciparum malaria. $A m \mathcal{F}$ Trop Med Hyg 1994; 50: 602-7.

15 Wilkins BH. Renal function in sick very low birth weight infants. 3. Sodium, potassium, and water excretion. Arch Dis Child 1992; 67: 1154-61.

16 White NJ, Warrell DA, Chanthavanich P, et al. Severe hypoglycaemia and hyperinsulinaemia in falciparum malaria. $N$ Engl f Med 1983; 309: 61-6.

17 Taylor TE, Molyneux ME, Wirima J, Fletcher KA, Morris $\mathrm{K}$. Blood glucose levels in Malawian children before and $\mathrm{K}$. Blood glucose levels in Malawian children before and
during the administration of intravenous quinine for during the administration of intravenous quinine for
severe falciparum malaria. N Engl $f$ Med 1988; 319: severe falci.

18 Brodehl JA, Franken A, Gellisen K. Maximal tubular reabsorption of glucose in infants and children. Acta Paediatr Scand 1972; 61: 413-20.

19 Orme ML. Side effects of quinine and derivatives. Acta Leidensia 1987; 55: 77-86.

20 White NJ, Waller D, Crawley J, et al. Comparison of artemether and chloroquine for severe malaria in Gambian children. Lancet 1992; 339: 317-21.

21 Hien TT, White NJ. Quinghaosu. Lancet 1993; 341: 603-8. 